\title{
Transient DNA breaks associated with programmed genomic deletion events in conjugating cells of Tetrahymena thermophila
}

\author{
Sergei V. Saveliev and Michael M. Cox ${ }^{1}$ \\ Department of Biochemistry, College of Agriculture and Life Sciences, University of Wisconsin, Madison, Wisconsin \\ 53706 USA
}

\begin{abstract}
Thousands of programmed genomic deletion events occur during macronuclear development in Tetrahymena thermophila. Two of the deleted segments, called $M$ and $R$, have been particularly well-characterized. Using ligation-mediated PCR, we have detected DNA strand breaks that correlate temporally and structurally with the deletion events in the $M$ and $R$ regions. The ends appear at positions that correspond precisely to boundaries of deleted sequences, as defined by observed chromosomal junctions found after deletion is complete. They occur exclusively during the known DNA rearrangement period in macronuclear development. The breaks are staggered by $4 \mathrm{bp}$ in the complementary strands. Several alternative breaks were found at the end of one deleted region, consistent with multiple alternative chromosomal junctions detected previously. The free $5^{\prime}$ ends generated at the breaks are phosphorylated. A purine residue always occurs at the free $3^{\prime}$ ends, with an adenosine appearing in 11 of 12 cases. Patterns found in the detected break sites suggest rules that define the ends of the deleted segments within a transposon-like deletion mechanism.
\end{abstract}

[Key Words: Ciliated protozoa; genomic rearrangement; DNA deletion; polymerase chain reaction]

Received September 22, 1994; revised version accepted December 13, 1994.

Ciliated protozoa provide examples of multiple types of programmed genomic rearrangements (Yao 1989; Prescott 1992). These organisms have two nuclei, a micronucleus and a macronucleus (for review, see Orias 1986). The micronucleus is transcriptionally inactive and is an analog of an inactive germ cell nucleus. The macronucleus is transcriptionally active and much larger in volume. Nutritional starvation induces cells of different mating types to undergo conjugation. The conjugants exchange haploid gametic nuclei to form diploid zygotic nuclei. Subsequent steps include mitotic divisions of $z y$ gotic nuclei, giving rise to new micronuclei and macronuclei. Old macronuclei are gradually degraded. In Tetrahymena thermophila, the entire process is completed in $\sim 20 \mathrm{hr}$ (Martindale et al. 1982).

The DNA rearrangements occur during the development of a new macronucleus and include the elimination of a substantial portion of the micronuclear genome (for review, see Prescott 1994). In T. thermophila, $\sim 15 \%$ of the genome is eliminated in $\sim 6800$ site-specific deletion events (Yao 1989). These average $2 \mathrm{~kb}$ in size and are scattered about the genome. Deletion of all the micronucleus-specific sequences occurs during a 2 -hr period of

\footnotetext{
${ }^{1}$ Corresponding author.
}

macronuclear development, commencing $\sim 10-12 \mathrm{hr}$ after mating is initiated (Austerberry et al. 1984). The mechanism by which the genomic deletions occur is unknown.

A number of distinct site-specific deletions in T. thermophila have been characterized recently at the sequence level (Yao 1989; Katoh et al. 1993; Heinonen and Pearlman 1994; Wells et al. 1994). Three separate deletions that have received much attention (Yao 1989) occur within a $10-\mathrm{kb}$ genomic region. They are designated L, M, and $\mathrm{R}$ for left, middle, and right, respectively. The $M$ region is the best studied. Here, two different deletion events may occur, deleting either 600 or 900 bp (Fig. 1). The $\mathrm{R}$ region undergoes a deletion of $1.1 \mathrm{~kb}$. The boundaries of the deleted segments are marked by short (up to $8 \mathrm{bp}$ ) terminal direct repeats, although these have no identified role in the deletion process. The deletion boundaries exhibit some microheterogeneity. There are at least two alternative deletion endpoints for each of the deletions illustrated in Figure 1 (Austerberry et al. 1989; Saveliev and Cox 1994). Short polypurine tracts, found 41-54 bp distal to each terminal repeat, are required for deletion and represent the only cis-acting sequences defined to date for a ciliate deletion reaction /Grodiska and Yao 1990|. Their location is an important factor in defining the deletion endpoints in the $M$ region /Godiska et 


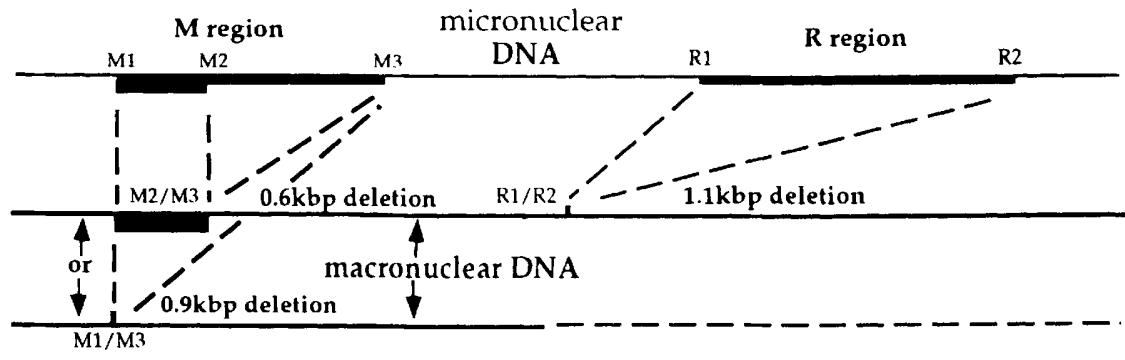

Figure 1. Schematic representation of programmed deletion events in the $M$ and $\mathrm{R}$ regions. There are two deletions in the $M$ region, of 0.6 and $0.9 \mathrm{~kb}$, and one deletion in the $\mathrm{R}$ region, of $1.1 \mathrm{~kb}$ (Austerberry and Yao 1987, 1988). Boundaries of deletions are labeled $\mathrm{M1}, \mathrm{M} 2$, etc., according to the scheme of Godiska and Yao (1990). Deleted regions are indicated by thick lines. al. 1993). The slight variation in the positioning of the polypurine tracts relative to deletion endpoints suggests the presence of another sequence element that helps define the deletion boundary. The polypurine tracts are absent in the neighboring $\mathrm{R}$ region.

Deleted sequences are degraded rapidly in $T$. thermophila and cannot be detected by Southern analysis (Austerberry et al. 1984). In the hypotrichous ciliates, Euplotes crassus and Oxytricha trifallax, the deleted segments are readily detected by Southern analysis as circular DNA species (Jaraczewski and Jahn 1993; Klobutcher et al. 1993; Williams et al. 1993). In Euplotes, the structure of the excised circles suggested a mechanism initiated with double-strand cleavage on both sides of the deleted region (Jaraczewski and Jahn 1993; Klobutcher et al. 1993). In Oxytricha, the results suggested a transposon-like mechanism with a doublestrand cleavage at one end of the deleted segment, followed by a direct attack of the liberated $3^{\prime}$-hydroxyl groups on phosphodiester bonds at the other segment boundary (Williams et al. 1993). Circular products of deletion can also be found in $T$. thermophila, but they occur at very low levels and are not products of the normal deletion pathway (Saveliev and Cox 1994; Yao and Yao 1994). The deleted segments are probably released as linear DNA species in Tetrahymena.

Cleavage of the DNA to initiate a deletion event should leave a transient break in the DNA. In this study we have used ligation-mediated PCR (LM PCR) to detect and characterize a series of breaks that are associated with the $M$ and $R$ region deletion events in $T$. thermophila.

\section{Results}

\section{Overview}

The most sensitive method available for the detection of transient breaks in genomic DNA is ligation-mediated PCR (Mueller and Wold 1989). The strategy, outlined in Figure 2, specifically detects free $5^{\prime}$ ends that are phosphorylated. The procedure requires a set of three separate primers to detect each strand break. A separate primer set was synthesized for each DNA strand at each deletion boundary, or six primers per boundary. Special precautions were taken to prevent nonspecific breakage of the genomic DNA during isolation, eliminating steps that would require unnecessary handling. DNA prepara- tions were analyzed immediately after isolation, because nonspecific breaks accumulated during storage (data not shown). Electron microscopy showed that DNA obtained by our procedure is $>10^{6}$ bp in length /data not shown). A variety of adaptations designed to accommodate the unique genome structure of Tetrahymena are described in Materials and methods.

\section{Detection of DNA strand breaks}

The population of conjugating cells was analyzed at different times after the initiation of conjugation. Results presented in Figure 3 for four DNA break sites are typical of those obtained in experiments done on 5 different sets of conjugating cells. At 9 and $11 \mathrm{hr}$ into the conjugation,

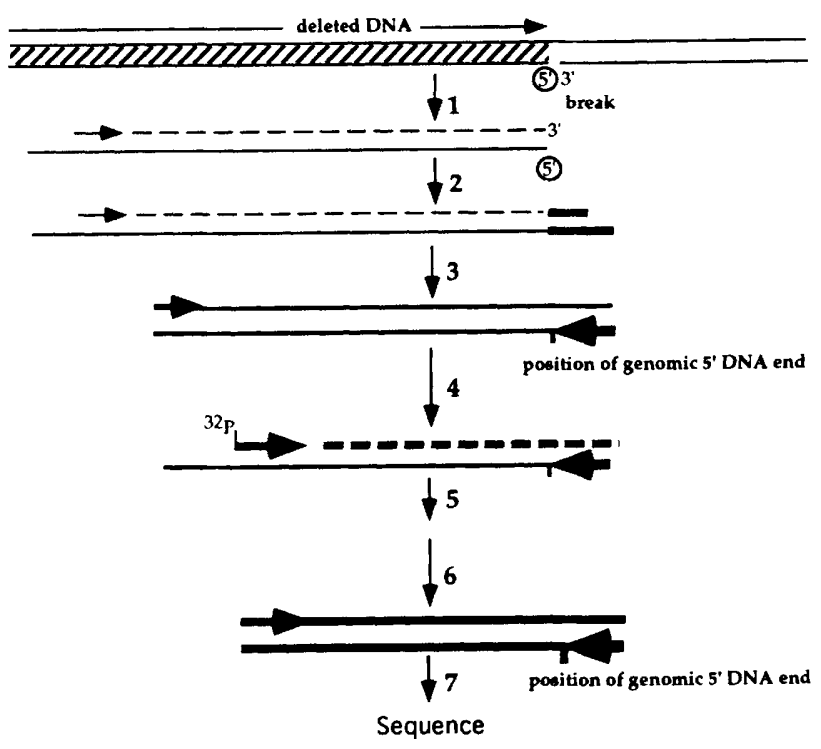

Figure 2. Ligation-mediated PCR procedure used to detect breaks. DNA cleavage during the deletions might occur in one strand or both; a break in only one strand is shown for simplicity. The steps are (1) denaturation of genomic DNA followed by annealing with the extension primer and primer extension, (2) ligation with a linker, (3) PCR amplification with an amplification primer and another oligonucleotide directed at the linker, and (4) visualization of the PCR products by primer extension of a ${ }^{32}$ p-labeled visualization primer and electrophoresis in a polyacrylamide gel. Sequencing of the PCR products requires several additional steps: (5) Extraction of the labeled DNA from the gel; (6) reamplification; and (7) direct sequencing of the PCR product of step 6. 


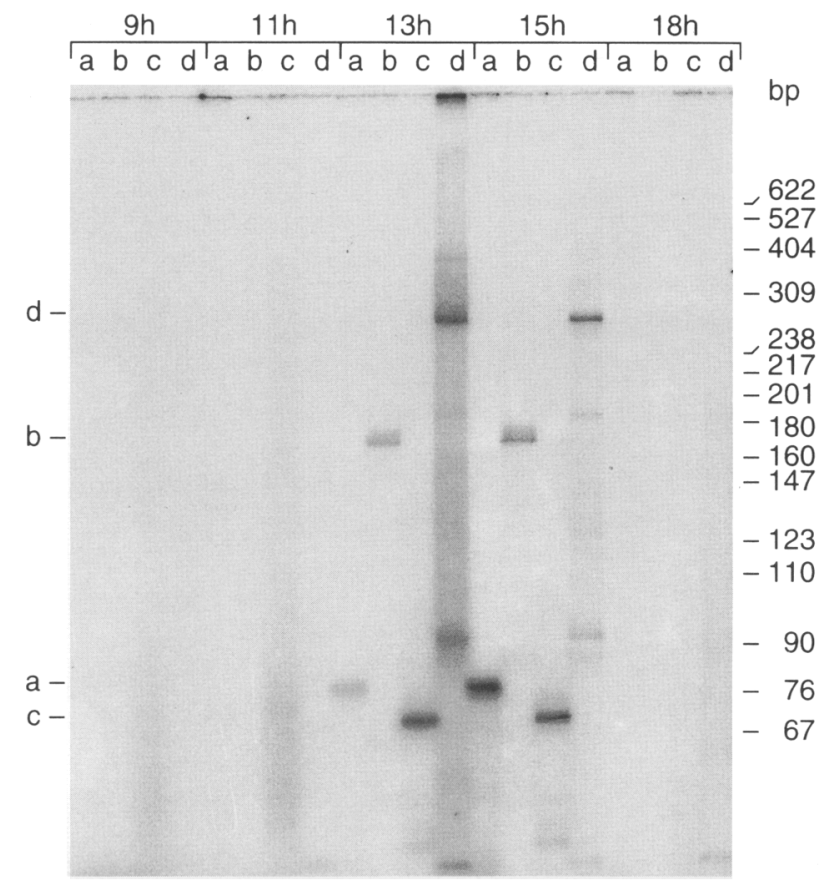

Figure 3. Temporal study of the generation of free $5^{\prime}$ ends in the $M$ and $R$ regions. Cell lysates were analyzed in different times in hours (h) after initiation of conjugation. R1B and R1T primer sets (see Materials and methods) were used to analyze the 5' DNA ends generated in either strand at the left boundary of the $\mathrm{R}$ region (R1; lanes labeled $a$ and $b$, respectively). M2B and M2T primer sets were used to detect the ends generated in either strand at the $\mathrm{M} 2$ boundary in the $\mathrm{M}$ region (lanes labeled $c$ and $d$, respectively|. Each band reflecting the relevant $5^{\prime}$ end in lanes $a-d$ is identified by a lettered marker at left. Molecular size markers were derived from an MspI digestion of the plasmid pBR322.

the only signal observed was the low-level smear originating from a background of nonspecific DNA breakage in all DNA preparations. The same result was obtained during analysis of starved cells, which do not undergo programmed deletions, in seven separate trials (data not shown).

Specific and reproducible PCR products appeared at 13 hr (Fig. 3). Their size in each case corresponded closely with the known boundaries of the deleted $M$ or $\mathrm{R}$ segments. The breaks persisted into the 15 -hr time point and disappeared by $18 \mathrm{hr}$ (Fig. 3), so that their appearance also correlated well with the period during which the deletions are known to occur (Austerberry et al. 1984). As shown by the example in Figure 4, the major PCR products were highly reproducible in separate PCR amplifications with a single cell lysate, as well as with different lysates derived from separate conjugation trials. This degree of reproducibility was established for all of the breaks described below (data not shown). A background of minor bands showed up in some experiments (e.g., Fig. 3, lane d) and could be observed in almost all experiments with sufficiently long gel exposures. Reproduction of these signals was less reliable. Some back- ground signals are expected in these experiments, arising from random breaks generated during DNA isolation. Primers directed to sequences retained in the macronucleus might also pick up breaks associated with the degradation of old macronuclei, a process that coincides temporally with development of new macronuclei. However, these competing processes do not occur at levels that would impede detection of breaks occurring specifically at the ends of the $M$ or $R$ regions.

\section{Mapping of the DNA breaks}

The major PCR products were sequenced to pinpoint the phosphodiester bond where each break occurred. Multiple PCR products from different trials were sequenced in each case to establish that the sequences were reproducible and invariant. Figure 5 illustrates the analysis of one break detected in the $\mathrm{R}$ region. The PCR product contained the expected genomic sequence, ligated to the $3^{\prime}$ end of the oligonucleotide linker used in the ligation step of LM PCR. The breakpoints defined by the linker/genomic DNA junctions are summarized in Figure 6. A total of 12 breaks were detected and mapped, all occurring at the boundaries of the deletions. For every break identified, there was another on the complementary strand, staggered by $4 \mathrm{bp}$. The microheterogeneity demonstrated previously in the chromosomal junctions left behind by deletion (Austerberry et al. 1989; Saveliev and Cox 1994) was reflected in the observed break sites. All

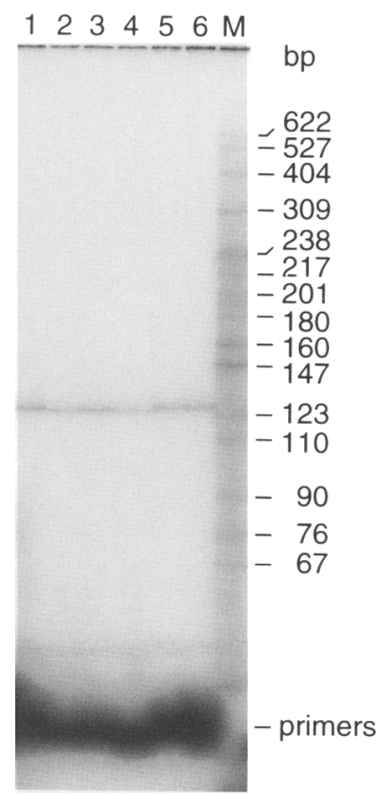

Figure 4. Reproducibility in the products generated by LM PCR. Cell lysates were obtained at $15 \mathrm{hr}$ after beginning of conjugation during the same (lanes 1-3) or a second (lanes 4-6) mating. The primer set $\mathrm{R} 2 \mathrm{~B}$, designed to detect a break on the bottom strand at R2, was used in the trial. The molecular size markers (lane $M$ ) are pBR322 fragments generated by MspI digestion. 


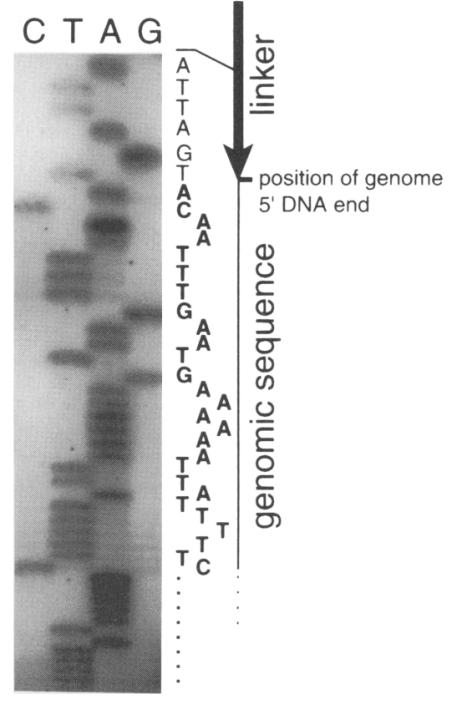

Figure 5. Sequencing analysis of the PCR products obtained during analysis of the upper strand at the $\mathrm{R} 2$ boundary.

of the chromosomal junctions summarized in Figure 6 have been detected in the same strains used in the present study to define DNA breakpoints (Austerberry et al. 1989; Saveliev and Cox 1994).

Several interesting patterns emerged:

1. In many instances, the 4 bp separating the staggered breaks at either end of a deleted segment were not homologous. The chromosomal junctions left behind by deletion can be viewed as a joining of ends at the breaks in the top strand or the bottom strand, but not both. For example, chromosomal junction 1 in the $\mathrm{R}$ region originates from splicing between ends 1 and 3 , both of which are located on the upper strand (Fig. 6). Chromosomal junction 2 results from splicing between ends 2 and 4, located on the bottom strand. With one exception noted below, every chromosomal junction described to date for the $M$ and $R$ regions corresponds to a putative link between ends defined by identified breaks in one of the two strands.

2. The $3^{\prime}$-end residue at each break is a purine. In 11 of 12 cases it is an adenosine.

3. Detected break 1 in the $M$ region was the only break that did not correspond to any known chromosomal junction. This was also the only break that had a guanosine as a 3 '-end residue.

4. For chromosomal junction 2 generated by the $0.6-\mathrm{kb}$ deletion, a corresponding break was found on the left side of the deleted segment but not on the right (Fig. 6C). No breaks were found at this position (which we have designated $\mathrm{M}^{\prime}$ ) on either DNA strand in 20 separate trials (a few shown in Fig. 7A) using several different batches of conjugating cells. This was not attributable to an inability to detect two different break sites that were close together, as seen in Figure 7B. We note that a break corresponding to the right end of this deletion would occur at a point where thymidines would be the $3^{\prime}$-end residues rather than adenosines (Fig. 6C).

5. At the left end of the $0.9-\mathrm{kb}$ deletion in the $\mathrm{M}$ region, there were two sets of staggered breaks. These breaks corresponded well to the three chromosomal junctions identified for this deletion event (Austerberry et al. 1989; Saveliev and Cox 1994|. Analysis of either
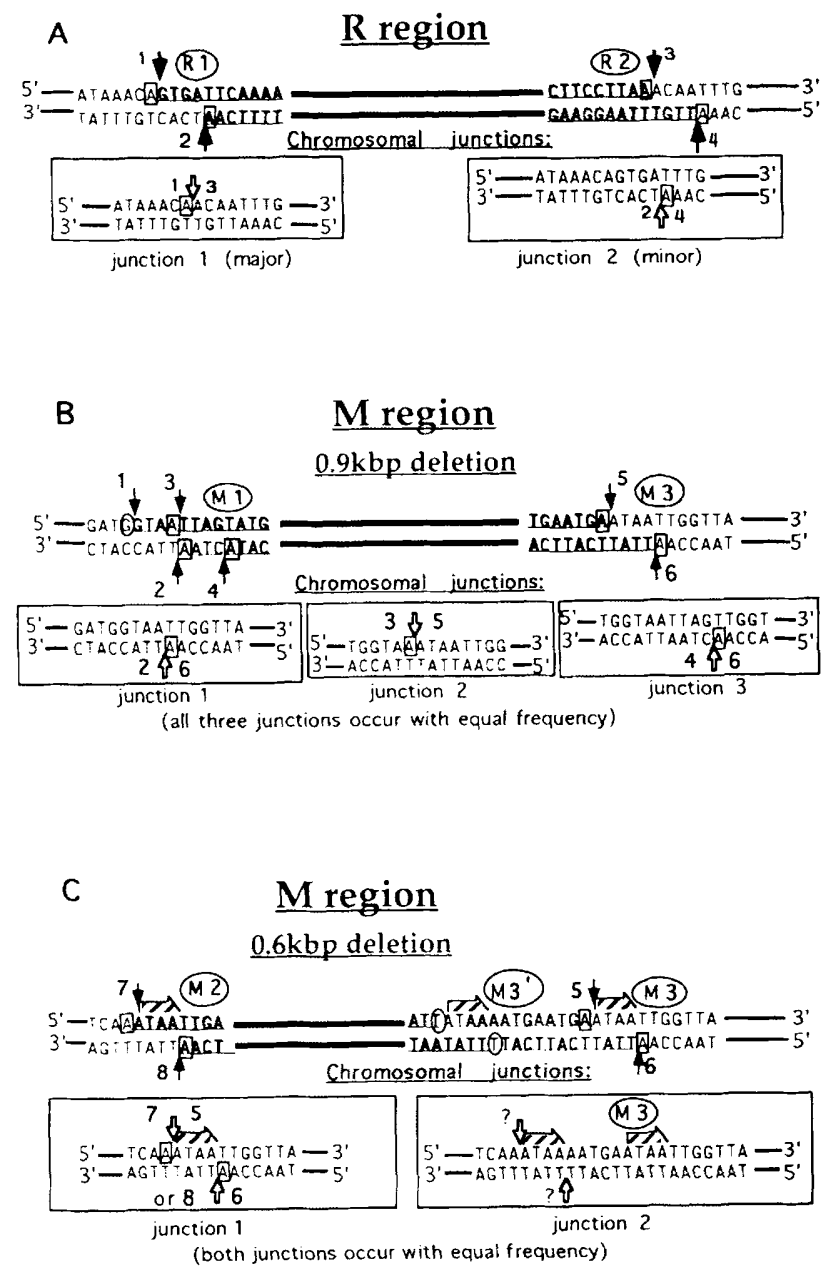

Figure 6. Map of the free 5' ends generated during programmed deletions in the $R$ and $M$ regions. Observed breakpoints are indicated by numbered solid arrows. The designations M1, M2, etc., denote deletion boundaries as in Fig. 1. The previously characterized chromosomal junctions left behind after deletion are also shown. Open arrows and the numbers flanking them indicate the presumed convergence of ends that correspond to each chromosomal junction. Because the sequences between the staggered breaks are identical on both sides of the $M$ region $0.6-\mathrm{kb}$ deletion, there are two possible origins for each chromosomal junction (one on either strand). The question marks at junction 2 created by the $0.6-\mathrm{kb}$ deletion $(C)$ indicate that no breaks corresponding to the right side of the junction were detected (at the site labeled M3'). The boxed residues are the $3^{\prime}$ adenosines present at most of the identified break sites. The circled guanosine in $B$ is the one case where a guanosine is the 3 '-end residue at a break. The circled thymidine residues in $C$ are the $3^{\prime}$-end residues that would be generated if breaks occurred at site M3'. 
A

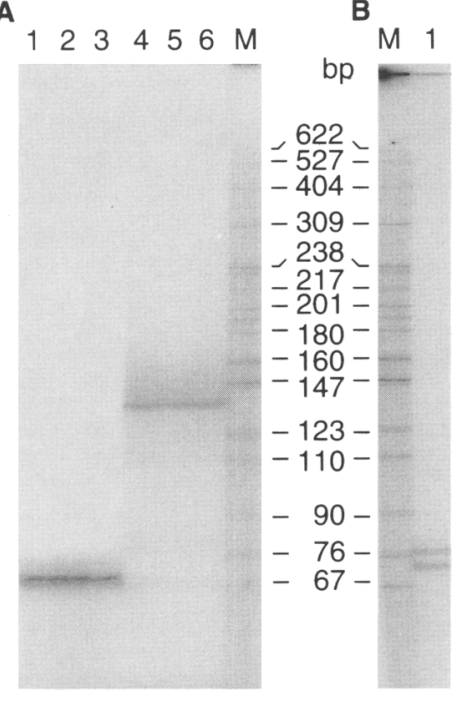

Figure 7. DNA strand breaks associated with the $0.9-\mathrm{kb}$ deletion in the $\mathrm{M}$ region. $(A)$ Breaks at the M3 boundary. The M3T and M3B primer sets were used to study the top (lanes 1-3) and bottom (lanes 4-6) strands. In both cases, the three lanes represent different trials from a single lysate from cells harvested 15 $\mathrm{hr}$ after conjugation was initiated. The PCR products correspond to breaks 5 (lanes 1-3) and 6 (lanes 4-6) (see Fig. 6, B and C). Breaks corresponding to deletion endpoint M3' would generate PCR products $13 \mathrm{bp}$ longer than those observed in lanes $1-3$, and 13 bp shorter than the PCR products shown in lanes 4-6. Lane $M$ contains molecular size markers as described in the legend to Fig. 4. (B) Breaks at the Ml boundary. The two PCR products observed were generated with the M1B primer set and correspond to breaks 2 (lower band) and 4 (upper band) shown in Fig. 6B. Molecular size markers are as in $A$.

strand at this end (designated M1) reproducibly revealed two PCR products in the same mixture (Fig. 7B|, which reflect the two different $5^{\prime}$ DNA ends.

\section{Discussion}

We have detected free $5^{\prime}$ DNA ends associated with programmed deletions in $T$. thermophila. They occur only in cells undergoing conjugation and only during the time when deletions are known to take place. They also correspond precisely with the boundaries of the deleted sequences, as defined by chromosomal junctions characterized previously.

The $5^{\prime}$ ends at the break sites are phosphorylated, because this is required for the method used to detect them. We cannot eliminate the possibility that breaks with 5 -hydroxyl groups were generated but not detected. However, most enzymatic DNA cleavage events generate phosphorylated 5' ends, including those associated with transposition (Mizuuchi 1992) and immunoglobulin gene rearrangements (Roth et al. 1993; Schlissel et al. 1993).

\section{The A rule}

As discussed further below, a $3^{\prime}$-end adenosine residue at each break site appears to play an important role in defining the precise deletion endpoints. The only detected break that did not have an adenosine at this position did not correspond to any known chromosomal junction. Even this exception, break 1 in the $M$ region, had a $3^{\prime}$ purine nucleotide. No breaks were detected at the right end of the $0.6-\mathrm{kb}$ deletion in the $M$ region at the position needed to generate chromosomal junction 2 . This was the only putative deletion endpoint where no 3 ' purines could be generated. In providing a potentially new sequence element to direct the initiating DNA cleavage, the A rule may explain the variability observed in the distance separating the cis-acting polypurine tracts from the deletion boundaries.

\section{A model for programmed deletions in $\mathrm{T}$. thermophila}

The information above and the patterns in Figure 6 impose enough constraints to suggest a model for the deletion reaction in the $\mathrm{M}$ and $\mathrm{R}$ regions (Fig. $8 \mathrm{~A}$ ). We propose that deletion is initiated with a double-strand cleavage at one end, with cleavage sites in each strand staggered by $4 \mathrm{bp}$. In the discussion below, the free 3 '-end residue that remains in the macronuclear DNA is abbreviated as the MAC $3^{\prime}$ end, whereas the $3^{\prime}$ end of the deleted micronuclear DNA is abbreviated as the MIC 3' end. The location of this cleavage is determined by the polypurine tract cis-acting sequences in the $M$ region and by the presence of adenosine residues separated by 4 bp in the complementary strands so that an adenosine residue appears at both the MAC and MIC $3^{\prime}$ ends. The $3^{\prime}$-hydroxyl end of the MAC adenosine residue is then used as a nucleophile in a transposon-like direct attack on the phosphodiester bond at the other end of the deleted segment and on the same strand. This single transesterification reaction on one strand defines the chromosomal junction. The processing events needed to complete the chromosomal junction are more speculative but would include cleavage of the other strand at a point $4 \mathrm{bp}$ distant from where the transesterification occurred. The mechanism has many features in common with that proposed for TBEl deletion in Oxytricha (Williams et al. 1993). The only difference is the absence of a second transesterification to circularize the deleted sequences in our pathway. Circular forms of the deleted segment occur at very low levels in Tetrahymena (Saveliev and Cox 1994; Yao and Yao 1994). Either the nicked circle generated in the proposed TBEl pathway is not generated in the $M$ and $R$ regions, or it is usually degraded rather than repaired.

An alternative model not shown is one in which the initial cleavage occurs on only one strand. Transesterification would generate the chromosomal junction in one strand. Processing steps would include cleavage of the other strand at both sides of the deleted segment. With this mechanism, we would not observe several of the breaks shown in Figure 6 unless they were generated during the processing steps.

The data provide several arguments against a mechanism in which double-strand cleavage occurs simulta- 
A

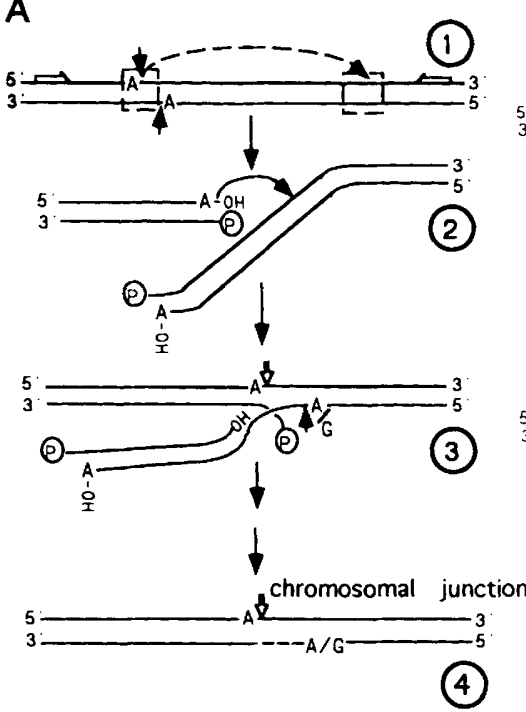

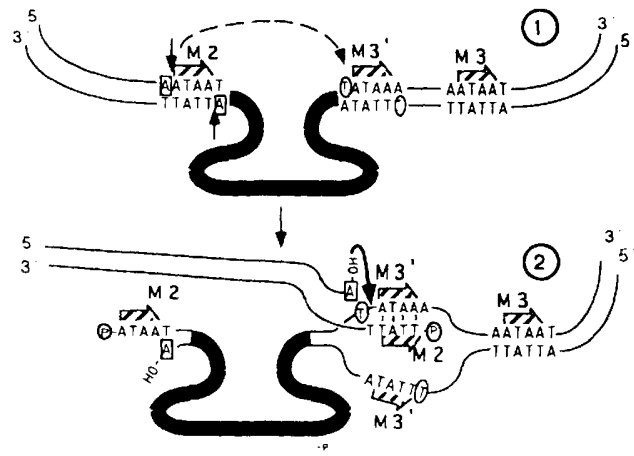

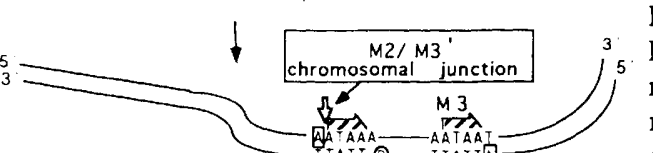

(3)

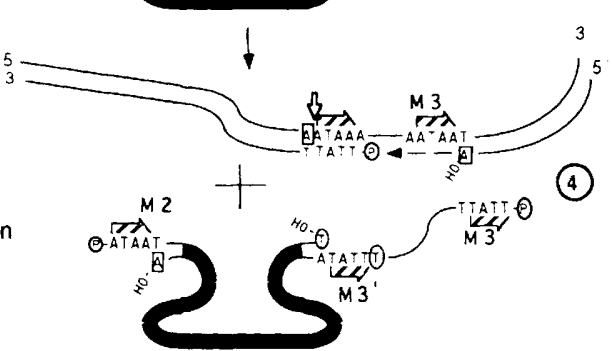

Figure 8. $(A)$ A model for programmed DNA deletion in T. thermophila. Solid arrows represent DNA cleavage; open arrows again indicate junctions created by deletion. Step 1 is a double-stranded DNA cleavage at a site defined by properly situated adenosine residues on either strand. Step 2 is a transposon-like transesterification that yields the final chromosomal junction on one strand. The second strand is processed in steps 3 and 4 . (B) A modified model for deletion between the M2 and $M 3^{\prime}$ sites. The differences come in steps 3 and 4 . In step 3 , the cleavage of the second strand is directed to M3 because no purine residues are suitably located near $M 3^{\prime}$. Repair DNA synthesis in step 4 must then fill in a somewhat longer gap than postulated for the other deletion events.

neously on both sides of the deleted segment, followed by ligation with or without processing / the latter would generate 4 bp of heteroduplex DNA). PCR amplification of the resulting chromosomal junctions would generate two alternatives at equal frequencies, with junctions located $4 \mathrm{bp}$ apart. Junctions 2 and 3 from the $0.9-\mathrm{kb} \mathrm{M}$ region deletion exhibit this relationship. However, junction 1 from the same region, formed by a joining of sequences on the bottom strand, has no counterpart junction that can be detected from the top strand. In the $\mathrm{R}$ region, junction 1 is found many times more efficiently than junction 2 (Austerberry and Yao 1987; Austerberry et al. 1989). In a recent study using the same strains as those used here, junction 2 in the $\mathrm{R}$ region was the only junction in Figure 6 that we did not detect /Saveliev and Cox 1994). In addition, we simply do not detect DNA breaks at one end of a $0.6-\mathrm{kb} \mathrm{M}$ region deleted segment in a position $\left(\mathrm{M}^{\prime}\right)$ required to explain one of the prominent chromosomal junctions. Although we cannot entirely rule out a model in which deletion is initiated by the generation of double-strand cleavage at both ends of the deleted segment (perhaps with the repair of any mismatched junctions favoring one strand or the other in a pattern consistent with the biases observed in chromosomal junctions|, the model in Figure 8 is more consistent with the available data.

The A rule would be especially important in directing the initiating cleavage. All of the chromosomal junctions can be explained by deletion events initiated by double-strand cleavage events generating $3^{\prime}$ adenosine ends on both strands. The lack of a chromosomal junction corresponding to breaks 1 and 5 in the $M$ region can be attributed to the $3^{\prime}$ guanosine residue at break 1 , which might preclude an initiating cleavage at that position. Whereas initiation can occur at either end of the deleted segment, factors other than the A rule must be operative in the $\mathrm{R}$ region to direct most initiation events to the left side. An initiating double-strand cleavage following the A rule is consistent with other Tetrahymena deletion events observed by Katoh et al. (1993) and Heinonen and Pearlman (1994). It is interesting to note that purine nucleotides play especially important roles in the RNA splicing reactions first characterized in $T$. thermophila (Cech 1990).

A modified A rule could affect the processing steps after transesterification. Cleavage of the second strand (Fig. 8A, step 3) could require an appropriately placed purine residue. A processing step cleavage event could explain the detection of break 1 in the $M$ region. Because the primers used to detect break 1 were targeted to sequences within the deleted segment, break 1 may simply represent the end of the deleted DNA. An operative A/G rule in the processing steps could also explain our failure to detect a break on the bottom strand at site M3'. Junc- 
tion 2 for the $0.6-\mathrm{kb} \mathrm{M}$ region deletion would be generated by double-strand cleavage at sites 7 and 8 , followed by transesterification. The absence of a properly placed purine on the opposite strand could direct the subsequent processing steps elsewhere, as outlined in Figure $8 \mathrm{~B}$.

Whether the ideas presented above prove to be correct in detail or not, the location of the DNA strand breaks provides important constraints in the ongoing effort to elucidate the mechanism of the deletion events. This information should also be useful in developing an in vitro system.

\section{Materials and methods}

\section{Cell lines}

Strains CU427.2VI and CU428.1VII were kindly provided by Peter Bruns. Cells were mated as described previously (Bruns and Brussard 1974). Cell cultures used in the experiments had a mating efficiency of not less than $90 \%$, as determined by microscopy.

\section{Isolation of genomic DNA}

The cells in $50 \mathrm{ml}$ of cell culture were collected by low-speed centrifugation $[1000 \mathrm{rpm}(250 \mathrm{~g})$ for $1 \mathrm{~min}$ in an IEC tabletop centrifuge, model HN-SII, equipped with a swinging bucket rotor] and resuspended in $10 \mathrm{ml}$ of NDS buffer [1\% SDS, $0.5 \mathrm{M}$ EDTA, $10 \mathrm{~mm}$ Tris-HCl (final $\mathrm{pH} 9.5$ ) $0.2 \mathrm{mg} / \mathrm{ml}$ of pronase) (Austerberry and Yao 1987). The cells were incubated at $60^{\circ} \mathrm{C}$ for 2-4 hr. The resulting lysate was transferred very gently to a dialysis bag and dialyzed for several hours against TE buffer (Sambrook et al. 1989) at room temperature. Room temperature was used to prevent the precipitation of SDS. The bag was then dialyzed in fresh TE buffer at $4^{\circ} \mathrm{C}$ overnight. The dialyzed lysate was used for LM PCR analysis. The DNA concentration was estimated by ethidium bromide fluorescent quantification analysis in $0.7 \%$ agarose gel, containing $1 \mu \mathrm{g} / \mathrm{ml}$ of ethidium bromide (Sambrook et al. 1989).

\section{Oligonucleotides}

Oligonucleotides were synthesized with an Applied Biosystem DNA/RNA synthesizer (A394) and purified in a polyacrylamide gel (Sambrook et al. 1989). The oligonucleotides used as primers in the study are as follows: R1Text, $5^{\prime}$-TGCTTAGAGTATCTTATTAATGAGATATTG-3'; RlTamp, 5' -CCTCAATTTACCTCATGTTGGCTATCT-3'; RITvis, 5'-CGGAAATACTTCGTTCATATTTATTTGTAT-3'; R1Bext, $5^{\prime}$-TACTAAATTATTCTTTATAATCTGACTCTT-3'; RlBamp, 5'-AATGAAATCTTAAGTTAGAATAGAAATTA-3'; R1Bvis, 5' -CCAAAAAGCTAATTAAAAATCAAAATCTATAAATC-3'; R2Text, 5'CGCATTAGTTTATAATCTCTTACCAAGTT-3'; R2Tamp, 5'GATTTACTGTAAGATAGTTCTAGAATAAGAC-3'; R2Tvis, 5'-GACAAAAATATTTTTGAAAAATAATTTTTTCATTC-3'; R2Bext, 5'-GTACTCCACAATATTCATAAATATTAGTCACTG-3'; R2Bamp, 5'-CAAGACTAAATGTTTGATATATTTCTAACTC-3'; R2Bvis, 5'-TAATTCACGTAATCAAGGACTACTAATATT-3'; MIText, 5'-GGAGATTTTCTTTAAGTCAAGGATGGAAAC-3'; MlTamp, 5'-CTCTATCTATACAAACACAGTTGATGGT-3'; M1Tvis, 5'-TGATGGTATTTTAATTTCAGGATTAGCAAT-3'; M1Bext, 5'-GCCATATTGAGTTGTTTATTCTGAAATTTATCC-3'; MIBamp, 5'-GGTACGATAGATCGACTGACGGTTTTA-3'; M1Bvis, 5'-GTAAATAAT-
AAGGAACCTCTTACTGTGATA-3'; M2Text, 5'-ATGTATTGATAAATCCAGGTATTGAAATTC-3'; M2Tamp, 5'-ATCTACGACAACCTATTGTACCACAC-3'; M2Tvis, 5' -TATCAGTTCTCATCAAGTTGTAATGCTA-3'; M2Bext, 5'-ATACCATCAACTGTGTTTGTATAGATAGAG-3'; M2Bamp, 5'TTGATGCCTTTTCTAATATTTTCAACTT- ${ }^{\prime}$; M2Bvis, 5' $^{\prime}$-T TTCCATCCTTGACTTAAAGAAAATCTCC-3'; M3Text, 5'AATCAATTTAATTAAGAAAAATTACTTTCA-3'; M3Tamp, 5'-GTTTAAAATAAGACTAATCTATAAATAAGG-3'; M3Tvis, 5'-GAGGGAGAAGGATTCAACAAAGTAAGC-3'; M3Bext, 5'-GTGTGGTACAATAGGTTGTCGTAGATTTTG-3'; M3Bamp, 5'-AAAGCAAGAAGGCTACTTAGCTTTCAAATT-3'; M3Bvis, 5' -GAATTTCAATACCTGGATTTATCAATACAT-3'; I, 5' -GGCTCGGACCGTGGCTAGCATTAGT-3'; I, 5'-ACTAATGCTAG-3'; I5, 5'-GGCTCGGACCGTGG-3' .

In the ligation-mediated PCR procedure below, oligonucleotides with the designations ext, amp, and vis were used for the extension step, the amplification step, and the visualization step, respectively. The letters $\mathrm{T}$ and $\mathrm{B}$ refer to the top and bottom strands with the DNA oriented as in Figure 1, and the designations $\mathrm{R} 1, \mathrm{Ml}$, etc., refer to the deletion endpoints that a given set of oligonucleotides was used to analyze.

\section{Ligation-mediated PCR}

The lysate generally contained $\sim 2.5 \mu$ g of genomic DNA $/ \mathrm{ml}$. A $200-\mu 1$ aliquot of the lysate was transferred very gently to a 0.5-ml PCR tube. The $1-\mathrm{ml}$ plastic pipette tip used for the transfer was cut to widen the opening to minimize DNA shearing. A mixture containing $11.2 \mu l$ of buffer $\mathrm{A}[0.8 \mathrm{M}$ Tris- $\mathrm{HCl}(\mathrm{pH} 9.0]$, $0.98 \mathrm{M} \mathrm{NaCl})$ and $1 \mu \mathrm{l}$ of extension primer $(1 \mu \mathrm{M})$ was transferred to the lysate. For primers targeted to sequences external to the deleted region, the concentration of extension primer was increased fivefold to partially compensate for the much higher concentration of macronuclear relative to micronuclear DNA in the genomic DNA isolates (Yao 1989). $\mathrm{NaOH}(3-5 \mu l$ of a $1 \mathrm{M}$ solution! was added to adjust the $\mathrm{pH}$ to 9.0. Mixing was provided by several slow inversions of the tube, and $\mathrm{pH}$ was estimated with indicator paper. The lysate was centrifuged for several seconds. DNA was then denatured at $95^{\circ} \mathrm{C}$ for $5 \mathrm{~min}$, and annealed at $55^{\circ} \mathrm{C}$ for $30 \mathrm{~min}$. The lysate was placed on ice, and $5.4 \mu \mathrm{l}$ of buffer B $0.41 \mathrm{M} \mathrm{MgCl}_{2}, 8 \mathrm{~mm}$ of each dGTP, dATP, $\mathrm{dTTP}$, and dCTP, $1 \mathrm{U} / \mu \mathrm{l}$ of sequencing grade Taq DNA polymerase (Promegall was added. The sequencing grade Taq polymerase, which lacks both $3^{\prime} \rightarrow 5^{\prime}$ and $5^{\prime} \rightarrow 3^{\prime}$ exonuclease activities, was used to help ensure the formation of perfect blunt ends in this step. After mixing, the lysate was microcentrifuged for several seconds. The extension step was carried out at $72^{\circ} \mathrm{C}$ for $7 \mathrm{~min}$. The tube was then transferred in ice. The lysate was treated with chloroform/isoamyl ethanol $(20: 1)$ and precipitated by 3 volumes of ethanol in the presence of $2 \mathrm{M}$ ammonium acetate and $100 \mu \mathrm{g} / \mathrm{ml}$ of glycogen at $-70^{\circ} \mathrm{C}$ for $2 \mathrm{hr}$. The precipitate was collected by microcentrifugation for $15 \mathrm{~min}$ at $4^{\circ} \mathrm{C}$, rinsed with $70 \%$ ethanol, and resuspended in $18 \mu \mathrm{l}$ of TE buffer. To this was added $2 \mu l$ of buffer $\mathrm{C}[0.3 \mathrm{M}$ Tris- $\mathrm{HCl}(\mathrm{pH} 7.7), 0.1$ $\mathrm{M} \mathrm{MgCl}_{2}, 0.1 \mathrm{M}$ DTT, $0.01 \mathrm{M} \mathrm{ATP}, 3 \mu \mathrm{M}$ anchor linker, 1.5 Weiss units $/ \mu$ l of T4 DNA ligase]. Ligation was carried out at $16^{\circ} \mathrm{C}$ overnight. The anchor linker was prepared by annealing the I and I oligonucleotides as described earlier (Mueller and Wold 1989). The ligated DNA was precipitated with 3 volumes of ethanol in the presence of $2 \mathrm{M}$ ammonium acetate at $-70^{\circ} \mathrm{C}$ for $2 \mathrm{hr}$ and collected by microcentrifugation. The DNA was redissolved in $50 \mu \mathrm{l}$ of PCR buffer $[0.4 \mu \mathrm{M}$ each of oligonucleotide I and the appropriate amplification primer; $0.2 \mathrm{mM}$ of each dGTP, dATP, dTTP, and dCTP; $2.5 \mathrm{mM} \mathrm{MgCl}_{2} ; 0.05 \mathrm{M} \mathrm{KCl} ; 0.01 \mathrm{M}$ Tris- $\mathrm{HCl}$ (pH 9.0); $0.1 \%$ Triton $\mathrm{X}-100 ; 10 \%$ glycerol]. The mix- 
ture was incubated at $94^{\circ} \mathrm{C}$ for $3 \mathrm{~min}$ and $55^{\circ} \mathrm{C}$ for $3 \mathrm{~min}$ and centrifuged, and $0.2 \mu \mathrm{l}$ (1 unit) of Taq DNA polymerase (Promega) was added. The mixture was covered with a layer of mineral oil and amplified by PCR for 35 cycles. Each cycle consisted of $1 \mathrm{~min}$ at $94^{\circ} \mathrm{C}, 1 \mathrm{~min}$ at $55^{\circ} \mathrm{C}$, and $1 \mathrm{~min}$ at $72^{\circ} \mathrm{C}$. Cycling was concluded with a final extension at $72^{\circ} \mathrm{C}$ for $5 \mathrm{~min}$. The PCR products were precipitated by ethanol in the presence of $2 \mathrm{M}$ ammonium acetate and resuspended in $50 \mu \mathrm{l}$ of extension buffer $[20 \mathrm{pmoles} / \mathrm{ml}$ of visualization primer end-labeled with $\left[\gamma^{-32} \mathrm{P}\right]$ ATP, $0.2 \mathrm{mM}$ each of dGTP, dATP, dTTP, and dCTP, 2.5 $\mathrm{mM} \mathrm{MgCl}_{2}, 0.05 \mathrm{M} \mathrm{KCl}, 0.01 \mathrm{M}$ Tris- $\mathrm{HCl}(\mathrm{pH} 9.0), 0.1 \%$ Triton $\mathrm{X}-100,20 \mathrm{U} / \mathrm{ml}$ of sequencing grade Taq DNA polymerase|. The mixture was incubated for $3 \mathrm{~min}$ at $94^{\circ} \mathrm{C}, 1 \mathrm{~min}$ at $55^{\circ} \mathrm{C}$, and 7 min at $72^{\circ} \mathrm{C}$. A portion of the mixture $(5 \mu l)$ was mixed with 3 $\mu l$ of sequencing stop solution (Sambrook et al. 1989) and analyzed by electrophoresis in 6\% PAAG under denaturing conditions. After electrophoresis, the extended products were visualized by exposure of the gel with X-ray film.

\section{Sequencing of $P C R$ products}

The ${ }^{32}$ P-labeled products of LM PCR were cut out of the gel and purified as described (Sambrook et al. 1989). The DNA was redissolved in the PCR buffer described above, except that the amplification primer was replaced by the visualization primer used in the final extension step. PCR amplification of the extracted DNA was carried out under conditions described above. PCR products were purified in a $6 \%$ polyacrylamide gel and sequenced directly by the Cycling Sequencing procedure (Promega). The primer used for sequencing was the ${ }^{32} \mathrm{p}$-endlabeled oligonucleotide I5.

\section{Acknowledgments}

We thank Peter Bruns for providing cell strains and Kathleen Karrer and colleagues in her research group for familiarizing us with the procedures used in the routine growth, maintenance, and mating of $T$. thermophila cells. We also thank Ross B. Inman for advice in the development of some of the procedures used to prepare DNA samples for the ligation-mediated PCR experiments.

The publication costs of this article were defrayed in part by payment of page charges. This article must therefore be hereby marked "advertisement" in accordance with 18 USC section 1734 solely to indicate this fact.

\section{References}

Austerberry, C.F. and M.-C. Yao. 1987. Nucleotide sequence structure and consistency of a developmentally regulated DNA deletion in Tetrahymena thermophila. Mol. Cell. Biol. 7: 435-443.

1988. Sequence structures of two developmentally regulated, alternative DNA deletion junctions in Tetrahymena thermophila. Mol. Cell. Biol. 8: 3947-3950.

Austerberry, C.F., C.D. Allis, and M.-C. Yao. 1984. Specific DNA rearrangements in synchronously developing nuclei of Tetrahymena. Proc. Natl. Acad. Sci. 81: 7383-7387.

Austerberry, C.F., R.O. Snyder, and M.-C. Yao. 1989. Sequence microgeneity is generated at junctions of programmed DNA deletions in Tetrahymena thermophila. Nucleic Acids Res. 17: 7263-7272.

Bruns, P.J. and T.B. Brussard. 1974. Pair formation in Tetrahymena pyriformis, an inducible developmental system. I. Exp. Zool. 188: 337-344.

Cech, T.R. 1990. Self-splicing of group I introns. Annu. Rev. Biochem. 59: 543-568.
Godiska, R. and M.-C. Yao. 1990. A programmed site-specific DNA rearrangement in Tetrahymena thermophila requires flanking polypurine tracts. Cell 61: 1237-1246.

Godiska, R., C. James, and M.-C. Yao. 1993. A distant 10-bp sequence specifies the boundaries of a programmed DNA deletion in Tetrahymena. Genes \& Dev. 7: 2357-2365.

Heinonen, T.Y.K. and R.E. Pearlman. 1994. A germ line-specific sequence element in an intron in Tetrahymena thermophila. I. Biol. Chem. 269: 17428-17433.

Jaraczewski, J.W. and C.L. Jahn. 1993. Elimination of Tec elements involves a novel excision process. Genes \& Dev. 7: 95-105.

Katoh, M., M. Hirono, T. Takemasa, M. Kimura, and Y. Watanabe. 1993. A micronucleus-specific sequence exists in the 5 -upstream region of calmodulin gene in Tetrahymena thermophila. Nucleic Acids Res. 21: 2409-2414.

Klobutcher, L.A., L.R. Turner, and I. LaPlante. 1993. Circular forms of developmentally excised DNA in Euplotes crassus have a heteroduplex junction. Genes \& Dev. 7: 84-94.

Martindale, D.W., C.D. Allis, and P.J. Bruns. 1982. Conjugation in Tetrahymena thermophila: A temporal analysis of cytological stages. Exp. Cell Res. 140: 227-236.

Mizuuchi, K. 1992. Polynucleotidyl transfer reactions in transpositional DNA recombination. I. Biol. Chem. 267: 2127321276.

Mueller, P.R. and B. Wold. 1989. In vivo footprinting of a muscle specific enhancer by ligation mediated PCR. Science 246: 780-786.

Orias, E. 1986. Ciliate conjugation. In The molecular biology of ciliated protozoa (ed. J. G. Gall), pp. 45-84. Academic Press, Orlando, FL.

Prescott, D.M. 1992. The unusual organization and processing of genomic DNA in hypotrichous ciliates. Trends Genet. 8: $439-445$.

1994. The DNA of ciliated protozoa. Microbiol. Rev. 58: 233-267.

Roth, D.B., C. Zhu, and M. Gellert. 1993. Characterization of broken DNA molecules associated with $\mathrm{V}(\mathrm{D}) \mathrm{J}$ recombination. Proc. Natl. Acad. Sci. 90: 10786-10792.

Sambrook, J., E.F. Fritsch, and T. Maniatis. 1989. Molecular cloning: A laboratory manual, 2nd ed. Cold Spring Harbor Laboratory Press, Cold Spring Harbor, New York.

Saveliev, S.V. and M.M. Cox. 1994. The fate of deleted DNA produced during programmed genomic deletion events in Tetrahymena thermophila. Nucleic Acids Res. 22: 56955701.

Schlissel M., A. Constantinescu, T. Morrow, M. Baxter, and A. Peng. 1993. Double-stranded signal sequence breaks in $V(D) I$ recombination are blunt, 5'-phosphorylated, RAG-dependent, and cell cycle regulated. Genes \& Dev. 7: 2520-2532.

Wells, J.M., J.L.E. Ellingson, D.M. Catt, P.J. Berger, and K.M. Karrer. 1994. A small family of elements with long inverted repeats is located near sites of developmentally regulated DNA rearrangement in Tetrahymena thermophila. Mol. Cell. Biol. 14: 5939-5949.

Williams, K., T.G. Doak, and G. Herrick. 1993. Developmental precise excision of Oxytricha trifallax telomere-bearing elements and formation of circles closed by a copy of the flanking target duplication. EMBO I. 12: 4593-4601.

Yao, M.-C. 1989. Site-specific chromosome breakage and DNA deletions in ciliates. In Mobile DNA (ed. D.E. Berg and M.M. Howel, pp. 715-734. American Society for Microbiology, Washington, D.C.

Yao, M.-C. and C.-H. Yao. 1994. Detection of circular excised DNA deletion elements in Tetrahymena thermophila during development. Nucleic Acids Res. 22: 5702-5708. 


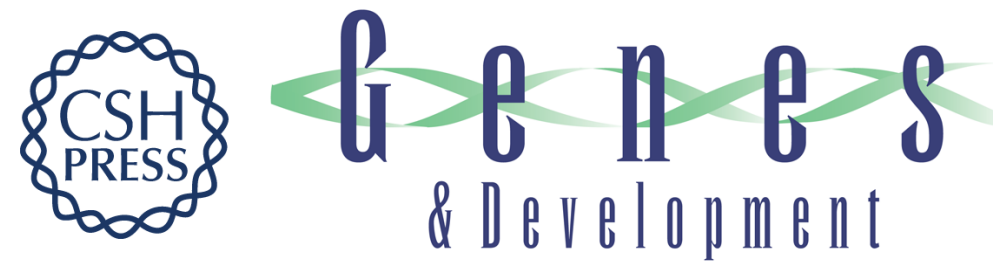

\section{Transient DNA breaks associated with programmed genomic deletion events in conjugating cells of Tetrahymena thermophila.}

S V Saveliev and M M Cox

Genes Dev. 1995, 9:

Access the most recent version at doi:10.1101/gad.9.2.248

References This article cites 23 articles, 12 of which can be accessed free at:

http://genesdev.cshlp.org/content/9/2/248.full.html\#ref-list-1

License

Email Alerting

Service

Receive free email alerts when new articles cite this article - sign up in the box at the top right corner of the article or click here.

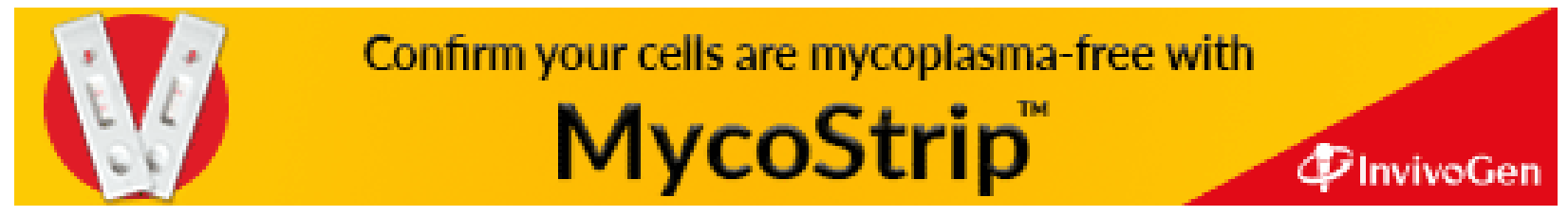

